\title{
Misfits Between Doctoral Students and Their Supervisors: (How) Are They Regulated?
}

Christelle Devos

Université catholique de Louvain Louvain-la-Neuve, Belgium

christelle.devos@uclouvain.be

Nicolas Van der Linden

Université Libre de Bruxelles

Bruxelles, Belgium

nivdlind@ulb.ac.be

Assaad Azzi

Université Libre de Bruxelles

Bruxelles, Belgium

aazzi@ulb.ac.be
Gentiane Boudrenghien

Université catholique de Louvain

Louvain-la-Neuve, Belgium

gentiane.boudrenghien@uclouvain.be

Mariane Frenay

Université catholique de Louvain

Louvain-la-Neuve, Belgium

mariane.frenay@uclouvain.be

Benoit Galand

Université catholique de Louvain

Louvain-la-Neuve, Belgium

benoit.galand@uclouvain.be

\section{Olivier Klein \\ Université Libre de Bruxelles \\ Bruxelles, Belgium \\ oklein@ulb.ac.be}

\begin{abstract}
(CC BY-NC 4.0) This article is licensed to you under a Creative Commons Attribution-

NonCommercial 4.0 International License. When you copy and redistribute this paper in full or in part, you need to provide proper attribution to it to ensure that others can later locate this work (and to ensure that others do not accuse you of plagiarism). You may (and we encourage you to) adapt, remix, transform, and build upon the material for any non-commercial purposes. This license does not permit you to use this material for commercial purposes.
\end{abstract}

Abstract

The purpose of the present study is to explore the "misfits" occurring between doctoral students and their supervisors. More precisely, we investigate the types of incongruences that occur, whether and how they are regulated and their consequences on students' outcomes. Qualitative interviews were conducted with 21 former $\mathrm{PhD}$ students (8 completers and 13 non-completers). Results show that, when facing a misfit, PhD students either (1) learn to live with it and/or turn to alternate resources, (2) suffer from it without being able to address the problem with their supervisor, (3) address the issue with their supervisor and try to solve it in various ways, or (4) are unable to address the issue because it reached a point of no return. Further, types of misfit regulation are likely to have an influence on students' motivation and engagement. These results are discussed in the light of person-environment fit, coping, emotional regulation, and conflict management frameworks.

Keywords: $\mathrm{PhD}$ students, doctoral attrition, supervisor support, fit, coping

Editor: David H. Kahl, Jr., Submitted: July 28, 2016; Revised: November 21; Accepted: December 9, 2016 


\section{Introduction}

The doctoral student's supervisor may be considered as "one of the most important persons - if not the single most critical person - with whom doctoral students will develop a relationship during their doctoral degree program" (Barnes \& Austin, 2009, p. 297). Numerous studies have showed the critical influence of advisors' supporting style on various $\mathrm{PhD}$ students' motivation and achievement (Bair \& Haworth, 2004; Devos et al., 2015; Hollingsworth \& Fassinger, 2002; Jairam \& Kahl, 2012; Jones, 2013; Martinsuo \& Turkulainen, 2011; Paglis, Green, \& Bauer, 2006; Sambrook, Stewart, \& Roberts, 2008; Wao \& Onwuegbuzie, 2011). In a longitudinal study over five years, Paglis et al. (2006) found that the quality of advisors' supervision had an impact on $\mathrm{PhD}$ students' research productivity, career commitment, and self-efficacy. In a qualitative study, Jairam and Kahl (2012) underlined the role of advisors' professional support, that is, feedback, advice, and problem-focused assistance in doctoral students' completion.

Yet, several authors have stressed that doctoral supervision is not a unilateral but a bilateral process; a complex interaction that is open to mutual adjustment, change and negotiation (Acker, Hill \& Black, 1994; Deuchar, 2008; Kam, 1997). According to Martinuso and Turkulainen (2011), "it is not supervisor behaviour as such that explains degree progress, but its interplay with the students' expectations and characteristics" (p. 106). In this direction, Pyhältö, Vekkaila, and Keskinen (2012) recently stressed the role of the degree of fit between the students and their supervisors. Their study is based on the Person-Environment (P-E) fit framework, which stresses the importance of the congruence between the individual and his environment (Edwards, 2008). A large number of doctoral students $(\mathrm{N}=1184)$ and supervisors $(\mathrm{N}=431)$ completed a survey composed of open-ended questions and Likert-type statements. They found that the degree of "the fit between the doctoral students' and supervisors' perceptions of resources and challenges is linked to the doctoral students' satisfaction with their studies and the supervisory relationship" (p. 395).

Using this approach, this last body of research has shed a new light on doctoral students' supervision. While most studies have addressed the influence of the supervisor's characteristics (e.g., supporting style) on doctoral students' outcomes, the line of research considering supervision as a bilateral process (e.g., Pyhältö et al., 2012) has highlighted the importance of considering the way (a) supervisor practices are perceived by the students and (b) the extend that these practices fit with students' own perspectives and needs.

\section{Person-Environment Fit}

According to Greguras and Diefendorff (2009), "the match between employees and their work environment is one of the most widely researched topics in organizational behavior" (p. 465). Person-Environment (P-E) fit (or misfit) has been defined as "the congruence, match or similarity between the person and environment" (Edwards, 2008, p. 168) or "the compatibility between people and organizations that occurs when: (a) at least one entity provides what the other needs, or (b) they share similar fundamental characteristics, or (c) both" (Kristof, 1996, pp. 4-5).

This general definition has been distinguished in terms of supplementary fit and complementary fit. Supplementary fit refers to the similarity between the person and the environment. Complementary fit is further divided into the needs-supplies fit (i.e., the comparison between the desires, values and goals of the person and the environmental supplies that serve as rewards for those needs) and the demands-abilities fit (i.e., the comparison between the demands of the environment and the knowledge, skills or energy of the person) (Edwards, 2008; Edwards, Cable, Williamson, Lambert, \& Shipp, 2006). Further, the P-E fit can be subdivided into person-vocation fit, person-job fit, person-organization fit, person-group fit, and person-supervisor fit (Kristof-Brown, Zimmerman, \& Johnson, 2005). The last dimension, which is the one of interest in the present 
study, refers to value congruence, personality similarity and goal congruence between a person and his/her supervisor (Kristof-Brown et al., 2005).

Overall, the literature on Person-Environment fit shows a positive influence of fit, and a negative impact of misfit, on workers' outcomes (e.g., attitudes, performance, withdrawal behaviours, strain, tenure) (Kristof-Brown et al., 2005). Yet, little is known about how individuals react to and cope with these misfits. What happens when they occur? How do people react when they feel or perceive a mismatch? Can misfits be addressed and solved by the protagonists? How does that occur? The purpose of the present study is to explore, beyond the types of misfit that are experienced, how doctoral students and their supervisors react to those situations and what are the consequences of these reactions on students' motivation and persistence in the doctoral journey.

In order to address these questions, misfits will be considered in the light of the PersonEnvironment fit framework, but also from the perspective of conflict management, coping, and emotion regulation frameworks. These frameworks identify different way of adjusting to those relationships lacking synergy that are likely to lead to different outcomes.

\section{Conflict Management}

Because we are considering misfits between two persons (and not between a person and an organization) and we are interested in how these situations may be resolved, the literature on conflict management is likely to help us understand this issue. Conflict is defined as "an interactive process manifested in incompatibility, disagreement, or dissonance within or between social entities (i.e., individual, group, organization, etc.)" (Rahim, 2002, p. 207). A conflict may for example occur "when two parties have partially exclusive behavioral preferences regarding their joint actions", or "when a party is required to engage in an activity that is incongruent with his or her needs or interests" (Rahim, 2002, p. 207).

Different types and dimensions of conflicts have been identified. Conflicts can for example refer to relationship issues (e.g., personal taste, values, and interpersonal style) or to task issues (e.g., judgment and interpretation of facts, distribution of resources) (De Dreu \& Weingart, 2003). Further, the literature on conflict management sheds light on different ways of handling conflicts. Rahim (2002) identifies five styles, based on protagonists' concern for self and others: integrating (i.e., examination of differences to reach an effective solution for both parties), obliging (i.e., playing down the differences and emphasizing commonalities; satisfying the concern of the other party and neglecting one's own concern), dominating (i.e., win-lose situation; forcing behaviour to win one's argument), avoiding (i.e., withdrawal, sidestepping), and compromising (i.e., both parties giving up something to make a mutually acceptable decision).

\section{Coping and Emotion Regulation}

Another line of research that offers a framework to understand how people cope with the difficulties they are confronted with (e.g., misfits with the supervisor) is the literature on coping and emotion regulation. Coping refers to how people deal with stressful events and emotions. It can be defined as the "constantly changing cognitive and behavioural efforts to manage specific external and/or internal demands that are appraised as taxing or exceeding the resources of the person" (Lazarus \& Folkman, 1984, p. 141). Originally, Lazarus and Folkman (1984) distinguished problem-focused coping (i.e., doing something to alter the source of stress) from emotion-focused coping (i.e., reducing or managing the emotional distress that is associated with the situation). Since then, multiple coping strategies have been pointed out in the literature. In an extensive review, Skinner, Edge, Altman, \& Sherwood (2003) identified thirteen potential families of coping, including five core ones: problem solving (i.e., taking direct and instrumental actions, making decision and planning to solve the problem), support seeking (i.e., seeking help or comfort from 
relatives), escape-avoidance (i.e., efforts to disengage or stay away from the stressful transaction), distraction (i.e., engaging in an alternative pleasurable activity), and positive cognitive restructuring (i.e., active attempts to change one's views of a stressful situation in order to see it in a more positive light).

In the same vein, authors working in the area of emotional regulation (Gross, 2013) assume that people regulate their emotions using five families of processes: situation selection (i.e., approaching or avoiding situations), situation modification (i.e., active efforts to modify the situation), attentional deployment (i.e., distraction, concentration or rumination), cognitive change (i.e., modifying the evaluation of the situation), and response modulation (i.e., influencing physiological, experiential or behavioural response to the situation). These categories are therefore likely to help us understand how doctoral students react when experiencing mismatches with their supervisor.

\section{Objectives of the Present Study}

In sum, the existing literature informs us that the degree of fit between $\mathrm{PhD}$ students and their supervisors plays a key role in students' motivation and engagement in their doctoral work. Yet, little is known on what happens once a mismatch is experienced. The purpose of the present study is therefore to investigate, in light of several complementary frameworks (P-E fit, coping and emotional regulation, conflict management), whether and how misfits are addressed by the protagonists. More precisely, the following research questions will be addressed in the present study:

- RQ1: What types of misfits are reported by doctoral students?

- RQ2: What are doctoral students' reactions to those situations?

- RQ3: What are the consequences of those ways of regulating the misfits on students' motivation and persistence?

\section{Method}

In order to address our research questions, a qualitative research design was used. Semistructured interviews were conducted with 21 former $\mathrm{PhD}$ students from two Belgian universities, who either completed their doctoral dissertation (completers, $n=8$ ) or quit the process before finalizing it (non-completers, $\mathrm{n}=13$ ).

\section{Context}

The participants of the present study were working in two universities located in the Federation of Wallonia-Brussels (as education is managed at this level of the political structure) of Belgium. In Europe and elsewhere in the world, the issue of doctoral training has gained considerable importance in recent years (European Commission, 2001; Kehm, 2006). In Europe,

"the European University Association (EUA) has set up a membership activity dedicated to the development, advancement and improvement of doctoral education and research training in Europe. In the framework of the Bologna process, EUA launched in 2005, after extensive consultation through a structured bottom-up process, Conclusions and Recommendations on Doctoral Programmes for the European Knowledge Society, better known as 'Salzburg Principles'. These principles were confirmed and enriched, in 2010, in the Salzburg II Recommendations. The Salzburg Principles and Recommendations are widely endorsed and considered the most comprehensive set of guidelines on doctoral training that exist. They cover the nature of doctoral training, its structure and conditions for success." (European Commission, 2001, p. 4) 
This general framework is being taken up in policies and practices by the European countries (Andres, Bengtsen, del Pilar Gallego Castaño, Crossouard, Keefer, \& Pyhältö, 2015). The 2004 decree that organizes doctoral education in the Federation of Wallonia-Brussels is in line with the Salzburg principles. The doctoral students work in the following context. After secondary school, they need to succeed in gaining a bachelor's degree and a master's degree. They then apply and are accepted for a PhD. Either they are employed during six years by the university (and they have a part-time teaching assignment), or they benefit from a doctoral fellowship for a period of four years (and they have no teaching assignments). During the doctoral work, students must attend courses at a doctoral school, for a total of 60 credits (ECTS) before defending their dissertation. The final doctoral thesis consists in original research, generally composed of several empirical articles, of which one has been accepted in a peer-reviewed journal.

\section{Data Collection}

We sampled participants so that they reflected both the prototypical profiles of $\mathrm{PhD}$ students and the diversity of experiences and contexts PhD students are likely to work in. Diversity and balance were sought for the discipline of their PhD (8 from Sciences \& Technology, 7 from Social Sciences, 6 from Health Sciences), the type of funding they received ( 7 on research grants, 13 in research assistant positions, 1 without funding), their gender (12 women, 9 men), and the university they were working in. A summary of the participants' characteristics is presented in Table 1. Names of the participants were changed in order to ensure anonymity.

Table 1. Summary of the participants' characteristics

\begin{tabular}{|c|c|c|c|c|c|c|}
\hline NAME & GENDER & DISCIPLINE & FUNDING & AGE & DURATION & ENDING \\
\hline Amanda & $\mathrm{F}$ & Agronomy & Grant & 23 & 4 & $\mathrm{C}$ \\
\hline Amy & $\mathrm{F}$ & Management & $\begin{array}{l}\text { Research } \\
\text { assistant }\end{array}$ & & 1 & $\mathrm{~N}-\mathrm{C}$ \\
\hline Angie & $\mathrm{F}$ & Medical sciences & $\begin{array}{l}\text { Research } \\
\text { assistant }\end{array}$ & 24 & 3 & $\mathrm{~N}-\mathrm{C}$ \\
\hline Anna & $\mathrm{F}$ & Linguistics & Grant & 26 & 3 & $\mathrm{C}$ \\
\hline Carol & $\mathrm{F}$ & Psychology & $\begin{array}{l}\text { Research } \\
\text { assistant }\end{array}$ & & & $\mathrm{N}-\mathrm{C}$ \\
\hline Carrie & $\mathrm{F}$ & Medical sciences & Grant & 28 & 2 & $\mathrm{~N}-\mathrm{C}$ \\
\hline Cathy & $\mathrm{F}$ & Arts & $\begin{array}{l}\text { Research } \\
\text { assistant }\end{array}$ & 26 & 2 & $\mathrm{~N}-\mathrm{C}$ \\
\hline Faith & $\mathrm{F}$ & Public health & $\begin{array}{l}\text { Research } \\
\text { assistant }\end{array}$ & 31 & 6 & $\mathrm{C}$ \\
\hline Francis & M & Informatics & $\begin{array}{l}\text { Research } \\
\text { assistant }\end{array}$ & 23 & 2 & $\mathrm{~N}-\mathrm{C}$ \\
\hline Frankie & $\mathrm{F}$ & Psychology & $\begin{array}{l}\text { Part-time } \\
\text { research } \\
\text { assistant }\end{array}$ & 34 & 12 & $\mathrm{C}$ \\
\hline Gerald & M & Engineering & Grant & 23 & 4 & $\mathrm{C}$ \\
\hline Irvin & M & Medical sciences & Self-funded & 40 & 18 & $\mathrm{C}$ \\
\hline Jordan & M & Pharmacology & $\begin{array}{l}\text { Research } \\
\text { assistant }\end{array}$ & 28 & 3 & $\mathrm{~N}-\mathrm{C}$ \\
\hline Justin & M & Computing & Grant & 23 & 2 & $\mathrm{~N}-\mathrm{C}$ \\
\hline Lucas & M & Medical sciences & $\begin{array}{l}\text { Research } \\
\text { assistant }\end{array}$ & 29 & 5 & $\mathrm{~N}-\mathrm{C}$ \\
\hline
\end{tabular}




\begin{tabular}{|c|c|c|c|c|c|c|}
\hline NAME & GENDER & DISCIPLINE & FUNDING & AGE & DURATION & ENDING \\
\hline Luke & $\mathrm{M}$ & Engineering & $\begin{array}{l}\text { Research } \\
\text { assistant }\end{array}$ & 24 & 1 & $\mathrm{~N}-\mathrm{C}$ \\
\hline Marvin & M & Informatics & $\begin{array}{l}\text { Research } \\
\text { assistant }\end{array}$ & 25 & 2 & $\mathrm{~N}-\mathrm{C}$ \\
\hline Melody & $\mathrm{F}$ & Linguistics & Grant & 24 & 3 & $\mathrm{C}$ \\
\hline Nicholas & M & Mathematics & $\begin{array}{l}\text { Research } \\
\text { assistant }\end{array}$ & 28 & 7 & $\mathrm{C}$ \\
\hline Olivia & $\mathrm{F}$ & Agronomy & Grant & 23 & 1 & $\mathrm{~N}-\mathrm{C}$ \\
\hline Valerie & $\mathrm{F}$ & Psychology & $\begin{array}{l}\text { Research } \\
\text { assistant }\end{array}$ & 23 & 3 & $\mathrm{~N}-\mathrm{C}$ \\
\hline
\end{tabular}

Note. Age $=$ Age when starting the PhD. Duration $=$ Duration of the PhD before completion or departure (years). Funding $=$ Type of funding (Grant $=4$ years and full time research; Research assistant $=6$ years, part-time research and parttime teaching $)$. Ending $=$ issue of the doctoral process $(\mathrm{C}=$ Completion; $\mathrm{N}-\mathrm{C}=$ Non-completion $)$.
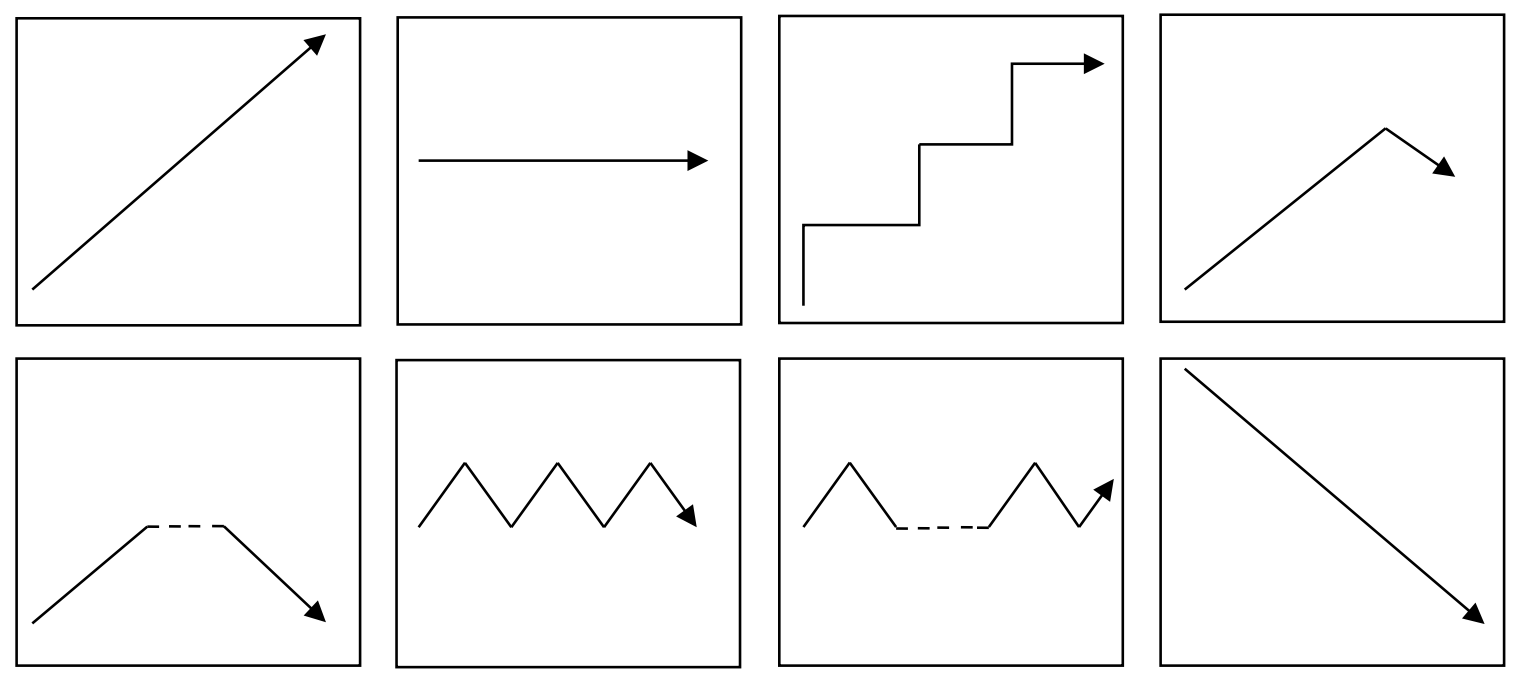

Figure 1. Figures adapted from Leclerc-Olive (2002) and used during the interviews in order to make participants sketch their own doctoral journey.

The interviews were conducted by the first three authors of the present article. They took place in the researchers' office or in the participants' office or house. An interview protocol was designed following the guidelines provided by Blanchet and Gotman (2010). First, the interviewer provided the participants with a short introduction to the study and ethical considerations (e.g., freedom to withdraw at any time). Second, we asked the participants to sketch their individual doctoral journeys. We presented participants with graphs that illustrate developments and changes over time (see Figure 1). These pictures were adapted from Leclerc-Olive (2002) and present an orthogonal axis with lines departing from the origin and taking different shapes and directions (e.g., a straight diagonal arrow, a wavy line, a dotted and broken line, an upward and then downward line and so forth). We then invited the participants to sketch the line(s) representing their own doctoral journey. Third, this drawing was used to support the subsequent discussion and sharing of experiences. The first question was to ask the participants to explain what they had drawn. Later during the interview, three other large open-ended questions were formulated: "What was a good/bad day for you during your PhD?" and "Have you ever considered quitting your PhD?" Between the open-ended questions, the discussion developed freely between the participant and the interviewer, punctuated by follow-up questions from the interviewer (e.g., what happened exactly, who was implicated, how did you feel, what did you do). The purpose was to address 
"what" and "how" questions and to understand the participants' experience from their own point of view (Blanchet \& Gotman, 2010). We also had a thematic guide (see Appendix) with a list of themes that had to be addressed in the interview (e.g., relations with the supervisors, teaching assignments). They were addressed in the end of the interview if they had not been before (Hsieh \& Shannon, 2005). The interviews lasted about one hour and were recorded. They were transcribed according to the guidelines of McLellan, MacQueen, and Neidig (2003) and Oliver, Serovich, and Mason (2005). Notes were taken by the interviewers before (to be aware of our possible biases) and after the interviews (to write down our spontaneous impressions).

\section{Data Analysis}

The data were analyzed using a thematic analysis approach (Boyatzis, 1998; Braun \& Clarke, 2006; Fereday \& Muir-Cochrane, 2006; Vaismoradi, Turunen, \& Bondas, 2013). Thematic analysis is "a method for identifying, analyzing and reporting patterns (themes) within data" (Braun \& Clarke, 2006, p. 79). This method is used to organize and describe the data in rich detail and to interpret various aspects of the research topic (Boyatzis, 1998; Braun \& Clarke, 2006).

First, data were read and listened to several times, writing down initial ideas for the coding and analysis. Second, codes and larger themes were identified. Several authors have pointed out that codes and themes can be identified either in an inductive or deductive way (Braun \& Clarke, 2006; Gilgun, 2005; Hsieh \& Shannon, 2005). Following authors such as Fereday and MuirCochrane (2006) and Zhou (2015), we used a combination of those two approaches. An initial set of categories was derived from the existing research on doctoral persistence, while new categories were allowed to emerge direct from the data using inductive coding. A dual focus on deductive and inductive approaches emphasized the dynamic dialogue between theory and data (Zhou, 2015). The initial set of codes, created in NVivo software, was therefore progressively amplified and amended as the transcripts were analyzed. This coding work was conducted by the two first researchers, who continually discussed the creation of new categories and their definition. Third, the themes were progressively refined; for example, some themes were collapsed into each other or broken down into separate themes. We checked that data within the themes cohered meaningfully and that there were clear and identifiable distinctions between the themes (Braun \& Clarke, 2006). A codebook with all the categories/sub-categories and their definitions was constituted. Finally, in order to answer the research questions of the present study, we focused on the categories that were relevant to these questions and analyzed in detail the data within them. Four categories were selected: "Support offered by the supervisor" (composed of various subcategories), "Inadequacy with the supervisor", "Regulation with the supervisor" and "Self-regulation". The content of those categories was transversally analyzed with regard to our research questions. Results are presented below.

\section{Results}

The results section proceeds in three steps; first, we describe and organize what we observed in the interviews; second, at the end of each section, we put them in relation with the existing literature; third, in the discussion, we integrate these results and interpret them together.

In our interviews, the $\mathrm{PhD}$ students reported professional and personal values (e.g., what they considered to be good research, what research should look like and be useful for), aspirations (e.g., the directions they wished to follow in their research), difficulties (e.g., specifying their research project and progressing in it), and needs and expectations with regard to supervisor support (e.g., some autonomy, help in structuring their ideas or answering their questions, a warm human relationship). The participants also reported on their supervisors' values, aspirations for the research project (e.g., what they considered to be a good direction to follow in the research, which is related to what is at stake for them), and their supervisory style (i.e., the attitude and 
behaviours that they initiated with the intention of helping the $\mathrm{PhD}$ students progress with their work).

We show below that (1) there can be a fit or a misfit between these respective perceptions, (2) various reactions to misfits may occur, and (3) the way misfits are addressed and eventually resolved is likely to have an influence on PhD students' outcomes.

\section{Fit or Misfit}

On the one hand, in some temporary or long-lasting situations there is a fit between these elements; the PhD students feel that they and their supervisors share the same values and aspirations for the research project, they report that they progress together in this direction, have similar ways of working, and the supervisory style matches the students' needs and expectations. In these situations, perceived supervisor attitude therefore plays a positive role in the doctoral students' motivation, engagement, progress and persistence.

On the other hand, in other situations, there is a perceived misfit between the $\mathrm{PhD}$ students and their supervisor. Three types of situations were identified.

First, there can be a mismatch between the students' and their supervisors' aspirations for the doctoral project, that is, in the directions that they consider to be promising, the specific subject they wish to investigate, the methodological approach they wish to use, etc.

Second, there can be incongruence between the supervisors' and students' values, their priorities in life, or their views of what constitutes good research. For example, the following participant (Valerie) reported how, in her view, misfits regarding research and life values kept growing between her supervisor and herself: "I realized that it did not make sense, she (her supervisor) just wanted significant results and I could not see the point of going in this direction. I started seeing her differently, which lasted until the end. (...) I started to see a discrepancy with my supervisor, I realized that we did not see life the same way, we did not have the same priorities. I started to think 'well, it is your choice, I am not judging you, but I am not heading toward a career like yours, this is not what I want' ".

Third, there can be a mismatch between the supervisor's supporting style and the students' needs and expectations for supervision. This mismatch may result from the two mismatches described above but may also arise for other reasons. For example, Angie experienced a mismatch between her supervisor's formal and distant way of managing the team and the human contact that she needed; "I am not a big fan of his team management style. It's not human enough for me. Because, ok, we are at work, do some work that needs to progress, but behind that, we also have a life, and we can't, well I can't leave my life aside and behave as if, during the 8-9-10 hours I am at work, it is the only thing that counts. That's not true, well for me personally it's a whole thing and that's it".

Analysis in the light of the existing literature. With regard to the theoretical frameworks on fit and conflict presented above, we suggest that the first type of misfit (between supervisors' and students' aspirations for the project) refers to task-related issues (De Dreu \& Weingart, 2003), while the second type of misfit (between supervisor's and students' values) refers to a relationship conflict. This second type of conflict is also in line with the literature on supervisorsubordinate similarity, which assumes that the more these two protagonists are similar on dimensions such as perspectives, work habits, or values, the higher is the subordinates' work satisfaction (Thompson, Brough, \& Schmidt, 2006). Finally, the second type of misfit (between supervisors' and students' values) corresponds to a supplementary fit, while the last type of misfit (between supervisors' support and students' needs for supervision) echoes a needs-supplies fit (Edwards et al., 2006). 


\section{Regulation or No Regulation}

Different reactions to this misfit will take place. Doctoral students may either (1) learn to live with it, (2) suffer from the situation without being able to address it with their supervisor, (3) address the problem and try to solve it in different ways, or (4) be unable to consider trying to regulate the issue as a point of no return in their disagreement has been reached. These processes are described below and illustrated in Figure 2.

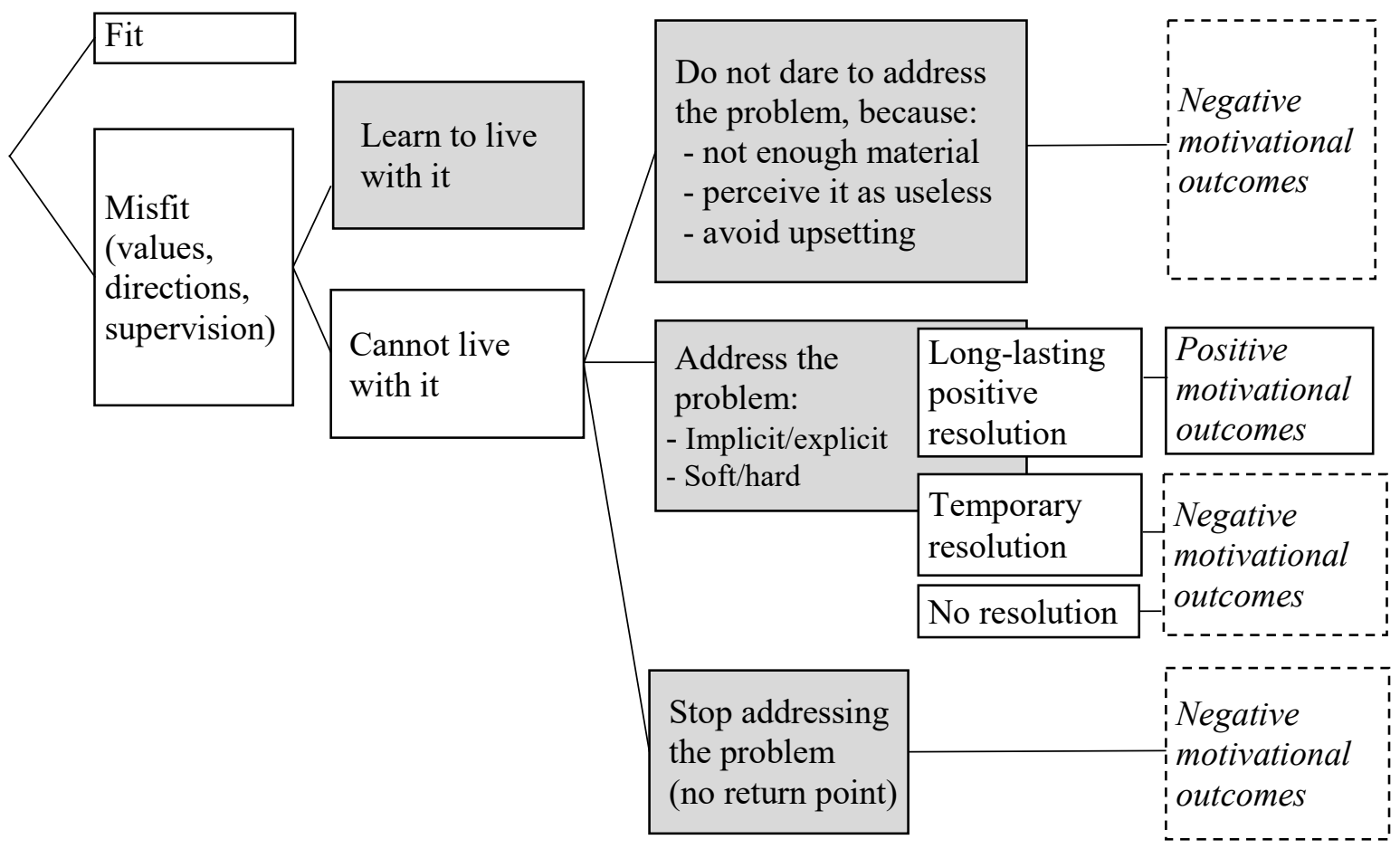

Figure 2. Summary of the (mis)fits, types of reactions and consequences on motivational outcomes.

\section{Learning to live with it}

In some situations, the $\mathrm{PhD}$ students take their supervisor's support and values as they are. They accept that they will not be able to change them or obtain more from her/him. They come to terms with what is on offer. They accommodate and deal with it. They consider it as a rule of the game, a constraint of the situation which they deal with without suffering from it. They sometimes reframe their perception of the situation and turn to alternative personal and external resources.

For instance, most of the participants stress the importance of receiving structuring support from their supervisor (e.g., receiving feedback on written production, answers to their questions) and wish they had received more of that type of help. Yet, reactions differ when they are confronted with a lack of such support from their supervisor (e.g., little time available, limited expertise in the student's doctoral subject, rare and superficial feedback). While some students keep criticizing this lack of support and suffer as a result, others manage to reframe their perception of the situation and turn to alternative personal and external resources. They realize that they will need to work by themselves and learn to live with it.

For example, Gerald was at first very upset by the lack of feedback he received from his supervisor during the last months of his $\mathrm{PhD}$, but then managed to change his perspective and deal with it; "I stopped harassing him with my questions and worked more by myself. I said to myself 'Now that I am in the last phase of my PhD, I should be able to do it by myself, I do not need to 
ask him so many questions or as much details as before"'. Another participant, Anna, also realized at some point that she could not get all the answers she needed from her supervisor and that she had to rely more on herself; "At a given moment, I resigned myself. Well, I said to myself 'It's my job to find my answers, he won't give them to me'. And I understood that in the end I was alone doing my research, well, 'alone', I mean that he would not offer me answers to those questions, and that I had to... I realized that we become experts in our field and that no one can answer our questions anymore".

Analysis in the light of existing literature. This first type of reaction (i.e., coming to terms with perceived misfits) is reminiscent of Skinner et al.'s (2003) positive cognitive restructuring and support-seeking types of coping. It also corresponds to other typologies of coping strategies that insist on this appraisal-focused type of coping (e.g., Moos \& Billings, 1982). The focus here is on changing the perception of the situation, adapting assumptions and cognitive reactions, redefining the meaning of the situation, altering the way one thinks about a problem (Skinner et al., 2003; Weiten, \& Lloyd, 2008). With regard to the emotional regulation framework, this type of reaction to misfits echoes the cognitive change step of the process model of emotion regulation. At this point, emotions can be regulated by performing cognitive reappraisal, that is, reinterpreting the meaning of the situation (Gross, 2013). Further, in the literature on doctoral studies, this type of behaviour supports Acker et al.'s (1994) findings that students often come to terms with whatever is on offer and display a variety of strategies for accommodating to the situation (e.g., turning necessity into a virtue and considering the lack of supervision as an opportunity to become more independent).

\section{Failing both to live with it and to address it}

In a number of cases, $\mathrm{PhD}$ students experienced a misfit with their supervisor (e.g., they realize that their values and views on the world differ completely, they disagree with the directions $\mathrm{s} / \mathrm{he}$ ask them to follow in their research, they are not satisfied with the type of support they receive from him/her, etc.) but they did not dare address the issue with their supervisor.

Several reasons led doctoral students to adopt this reaction. First, in situations where they need advice or feedback from their supervisors on their work, PhD students may consider that they do not have enough material or that their ideas are not mature enough to ask for a meeting with their supervisor. This can be a real problem among $\mathrm{PhD}$ students as it may turn into a vicious circle (i.e., they feel that they are not progressing well enough, this prevents them from asking support from their supervisor, which slows down their progress, etc.). For example, Justin did not feel very motivated by the subject that his supervisor had suggested to him, but did not dare let him know before he had a sound alternative subject to suggest to him; "I should have questioned (my project) even if I had no clear idea of what I wanted to do, but I didn't. I was waiting to have a clearer idea and in the meantime I was pursuing the original direction, and in the end demotivation came over me. (...) I was a bit scared to ask because I didn't have much to bring, so it's a bit of a vicious circle (...) I wish I had more input from my supervisor, but I never explicitly asked for it really so it is my fault as well". Progressively, this decreased his motivation and led him to quit his $\mathrm{PhD}$.

Third, in situations where the students might need to take a stand against their supervisor's requirements and assert their own ideas, they may be reluctant to do so because they believe it would be useless. For example, Loren, who was experiencing a very difficult and negative relationship with his supervisor, explained that "Sometimes I just thought 'Ok today I will keep my ideas to myself, shut up and do her experiment'. There were also meetings where I was going, listening to her, saying 'yes, yes' and left because, there was just no point saying something. I am not perfect either, I tried a couple of times (to express my ideas) but sometimes I did not feel like making the effort, that's true". 
Fourth, other reasons, at the relational level, may also prevent students from confronting their supervisor, such as avoiding upsetting or offending them. For example, Marc got on very well with his supervisor, who was making a lot of effort to help him in his PhD. His supervisor had suggested a new research subject to him as he could see that he was not making much progress on the first one. When Marc realized that he was not more interested in this second subject, he did not dare say so to his supervisor; "The problem I had is that I was thinking 'Ok I have been there for one year, we already changed subject once (laugh)', I could not imagine telling my supervisors 'Well you see, your subject, I'm not interested in it'. So I decided to stop my PhD because I felt there was no way to turn back. The subject was there, after one year it was not possible to... and in the end I never addressed this issue with my supervisors".

Interestingly, in these situations, the $\mathrm{PhD}$ students sometimes regretted that their supervisor did not take the initiative to ask them how they were doing when the supervisor saw that they were not doing well. For example, Olivia reported that when she was experiencing high levels of emotional distress, demotivation, and disengagement, she needed a helping hand from her supervisor; "If I was him, I would have come to me (laugh), well to ask 'Are you feeling all right, you are not very engaged anymore, where has your motivation gone?'. Sometimes I need to be shaken by someone".

Analysis in the light of existing literature. This second type of reaction to misfits (i.e., not daring to address them) recalls Skinner et al.'s (2003) escape-avoidance type of coping and Rahim's (2002) avoiding style of conflict management. According to Desivilya and Yagil (2005), while most research on conflict management has focused on active ways of handling conflicts, passive approaches are also frequent in work groups. For example, the authors mention that past studies "found that avoiding disputes, i.e., refraining from direct confrontation with conflict issues in formal or public sphere, was the prevailing mode of conflict management in organizations" (p. 57).

\section{Addressing the issue and initiating a regulation process}

Finally, in some situations, there is an attempt from the PhD students and/or their supervisor to address the issue and initiate a regulation process. In our material, we observe the following forms of interactions between the doctoral students and their supervisor, which lead to more or less positive resolutions of the misfits.

First, the regulating interaction may be either explicit (e.g., the PhD student or the supervisor asks for a meeting to discuss the issue) or implicit/informal (e.g., the PhD student or the supervisor hints at the issue during an informal discussion). This dimension can also characterize the regulation style of the relationship on the long run. For example, Amy initiated an explicit regulation of the situation; "I went to him several times saying 'something is wrong; we need to talk', I am within an ace of handing in my notice' (laugh)". Conversely, Gerald experienced an infor$\mathrm{mal} / \mathrm{implicit}$ regulation of a tense episode. He was expecting more feedback from his supervisor in the final phase of his dissertation and was frustrated not to receive it; "I wonder if there isn't a moment where, in a discussion, he nicely made me understand that I was going a bit too far. We were having a talk in our cafeteria and he told me 'hey, you are pressuring me with this stuff!, kind of saying... well a nice way of saying it... And as it was not usual, I clicked and said to myself "well, I should maybe leave him alone and work by myself"'.

Second, the regulating interaction can be "soft" or "hard"; that is, it can take the form of a timid breakthrough or an open controversy (e.g. in the cases where the $\mathrm{PhD}$ students open a procedure and make written reports in order to assert their rights). For example, Amanda experienced a challenging confrontation with her supervisor when she stated that she was stopping doing more experiments in order to be able to write her dissertation during the last three months of her con- 
tract; "Yes, I said stop. I said stop. It was a very hard time. I went back to my parents, wrote a letter to my supervisor to say stop, well I did not give it to him but it just helped me to clarify my thoughts to arrive Monday morning and tell him that is was over (...)”.

Third, the regulation attempts will either (a) fail (no agreement and no improvement of the situation), (b) end in a short-term improvement of the situation with the problem coming back in the longer term, or (c) end in a long-term improvement of the situation. For example, Olivia reported how she failed to make her supervisor understand her lack of interest for the subject; "I tried several times to let him know that I was not very interested in this stuff, but he was very intimidating, and the couple of times where I said 'no I do not want to do that, I would like to do it in a different way', bam, he talks, talks, talks, until I say 'yes, ok' (laugh). It always goes his way in the end".

Analysis in the light of existing literature. This third type of reaction to misfits (i.e., addressing them and initiating a regulation process) is in line with a problem-focused (Lazarus \& Folkman, 1984) or problem-solving (Skinner et al., 2003) type of coping. The person deals with the problem that is causing stress, and the aim is to change or eliminate the source of stress. It includes coping strategies such as taking control, instrumental action, direct action and decision making. This type of reaction also corresponds to the situation modification step in the process model of emotion regulation (Gross, 2013). Further, since an action is taken to address the misfit, a conflict management process is engaged and the protagonists display various conflict management strategies (e.g., integration, domination, compromise, etc.) (Rahim, 2002).

\section{Reaching a point of no return and ceasing to address the issue}

Finally, events (argument, clash, betrayal) may occur that reach such a high level of severity that, from the point of view of the $\mathrm{PhD}$ student, no regulation is ever possible. The conflict is seen as irreversible and this may lead the PhD students to put an end to their trajectory.

For example, Angie's doctoral journey ended up with a clash with her supervisor. There had always been a misfit between Angie's need for human relations and her perception of her supervisor as formal, cold, and work-oriented. One day, a personal problem prevented her from attending one of her teaching assignments, which made her supervisor very angry with her. She reported "I thought to myself 'what an [insult]', I am sorry but there are no other words, it really is what I said to myself, 'what an [insult]', he does not understand anything (...). And then I thought, 'Ok it is never going to work, we are not at all on the same wave length, forget it'. And that's it." And she quit.

Analysis in the light of existing literature. This fourth type of reaction to misfit is in line with the "escape" facet of the escape-avoidance type of coping, which consists in engaging efforts to disengage from the stressful transaction (Skinner et al., 2003). It also echoes Carver and Scheier's idea of adaptive disengagement from unattainable goals (Wrosch, Scheier, Miller, Schulz, \& Carver, 2003).

\section{Consequences on the Outcomes}

Beyond observing misfit experiences and various way of dealing with them, we found in our material that how these situations were addressed and eventually solved was related to $\mathrm{PhD}$ students' motivation, engagement, and progression with their doctoral work.

First, a lack of fit was, overall, related to students' outcomes. When discrepancies were reduced (e.g., the students managed to live with their supervisor's attitude or were able to put forward their own point of view), the students reported feeling satisfied and motivated. Conversely, unaddressed or unsolved misfits were associated with decreased student's motivation. For example, Marc remembered that he did not dare tell his supervisor that he was not much interested in the 
subject suggested by the supervisor, because he had no alternate subject to suggest. He therefore kept working on his own on this subject without much success and progressively lost his motivation; "I should have questioned [my project] even if I had no precise idea of what I wanted to do. But I did not, I kept waiting to find a more precise idea, and therefore, in the meantime, I kept working in this direction, and in the end demotivation got me".

Further, unaddressed or unsolved misfits may lead to growing misunderstandings, mutual recriminations, and vicious circles, where the inability to deal with the situation undermines students' motivation and engagement and results in stagnation, which in turn increases the supervisors' incomprehension and disengagement. For example, Luke suggests that "My supervisor, I think, probably realized that I was not motivated, and therefore put even less energy into the way he was supervising me and my research". In the end, these vicious circles and the degradation of both the relationship and the students' progress with their work may lead to drop out.

In order to have an overall view of the influence of misfit regulation on drop out, we compared the completers' and non-completers' experiences of supervision. We found that what differentiates the two groups is not so much what we can infer in terms of factual/objective supervision practices (e.g., frequency of meeting, amount of feedback) but more how the doctoral students fitted in and dealt with their supervisors' practice.

On the one hand, completers did not report higher quality supervision, but instead fitted in and dealt with the type of supervision that they were offered. Some of them were happy with the supervision they received (e.g., Gerald). Others were satisfied with it, even if, on the basis of what they reported, it did not reflect good supervisory practices (e.g., sporadic meetings, little feedback, laissez-faire style, etc.) (e.g., Faith). Still others were somewhat disappointed with some aspect of their supervision (e.g., lack of feedback) but came to terms with it and turned to other internal or external resources (e.g., Anna, Irvin, Melody, Nicholas). Finally, some PhD students were able to put forward their point of view (e.g., claim for more autonomy) (e.g., Frankie, Amanda). In these four situations, the doctoral students received support that fitted their needs or they were able to regulate the lack of fit. Being able to find an adequate balance between their needs and their environment made it possible for them to find and make progress in a research project that made sense to them.

On the other hand, the non-completers who experienced incongruences with their supervisors were not able to address or to solve them. Some of those students avoided addressing the problem with the supervisor (e.g., Francis, Luke, Marc, Cathy, and Justin). Others tried to address it, numerous times for some of them, but without being able to reach a long-lasting and mutually satisfactory solution (e.g., Valerie, Carol, Amy, Loren, Angie, John, Carrie, and Olivia). This inability to deal with the type of supervision they were offered impeded their progress with their doctoral work.

\section{Conclusion}

The purpose of the present research was to explore misfits occurring between $\mathrm{PhD}$ students and their supervisors. A large amount of research in organizational psychology has shown the negative consequences of lack of fit on workers' outcomes (Edwards, 2008). In the educational literature, past research has investigated the unidirectional influence of doctoral advisors' supervising style on PhD students' outcomes (Bair \& Haworth, 2004), and, more recently, the fit between advisors' and students' perceptions of resources and demands (Pyhältö et al., 2012). In the present study, we took those analyses one step further in analyzing the point of view of the PhD students on the types of misfits that doctoral students and supervisors were encountering, the students' reactions to them, the regulation processes, and the consequences on students' motivation and persistence. 
Results showed that, first, different types of misfits were experienced by the participants. The participants reported temporary or long-lasting lack of fit with regard to the environment (e.g., incongruence with the research project or the academic culture), the supervisor (e.g., incongruence between life- and work-related views and values, aspirations for the doctoral work) or the supervision (i.e., incongruence between the supervision offered and the students' needs and expectations). Second, as expected, we found that there were different ways of reacting to these misfits. As depicted in Figure 2, students may (1) learn to live with it (change their perception of the situation and/or turn to alternate personal or external resources), (2) fail both to live with it and to address the issue with their supervisor, because they tend to work on their own, they do not want to upset their supervisor, or because they think that it would be useless, (3) address the issue with their supervisor and try to solve it in different ways (implicit or explicit, soft or hard, with a more or less positive ending), or (4) be unable to consider trying to regulate the mismatch as they have reached a point of no return in their disagreement. Third, we found that whether and how discrepancies were regulated was associated with doctoral students' motivation and persistence.

We have seen that these results could be read in the light of the person-environment fit framework (Edwards, 2008), coping and emotional regulation theories (Gross, 2013; Skinner et al., 2003), conflict management literature (Rahim, 2002), and past research on doctoral studies. First, the present study has shown the relevance of considering fit between students and supervisors in the light of both fit theories and conflict management theories, as this type of fit/misfit occurs between two social entities. Second, we have seen that doctoral students' reactions to a lack of fit could be related to coping and emotional regulation strategies. In short, the four types of reactions depicted above can be related to core coping, emotional regulation, and conflict management strategies: (1) cognitive restructuring and support seeking, (2) avoidance, (4) escape and goal disengagement, and (3) situation modification and problem solving (in which doctoral students use conflict management strategies that will lead to more or less positive endings). Third, the results from the present study support the assumptions and findings from past studies that addressed doctoral supervision as a bilateral, complex, changing and negotiated process (Acker et al.,1994; Deuchar, 2008; Kam, 1997; Martinuso \& Turkulainen, 2011; Pyhältö et al., 2012), where both the students and the supervisors develop and learn from each other (Halse, 2011).

The main contribution of the present article was to offer an initial exploration into the complex interactions between doctoral students and their supervisors when facing misfits and to analyze their role in $\mathrm{PhD}$ students' motivation and persistence. However, the present study also suffers from limits that should be addressed in future studies. Our analyses were based on retrospective interviews, that is, on participants' self-reported recall of the doctoral experience. First, this material is therefore subjective and reflects the participants' perceptions of the reality rather than the reality itself. Second, the participants had to tell their story and were therefore likely to present it in a way that may be more coherent than it really is or that is self-protective. Third, we only had the doctoral students' point of view and it would have been interesting to enrich it with the supervisors' perspective on the misfit experiences (Bøgelund, 2015).

\section{Future Research}

Future research in several directions is needed to improve our understanding of this issue.

First, analyzing both the perceptions of $\mathrm{PhD}$ students and their supervisor would be of great value. It would offer a better understanding of the origin and the nature of the misfits; can they be ascribed to unconstructive behaviours on the part of the supervisor or to PhD students' maladjustment to the doctoral process?; do they reflect deep incompatibilities or only superficial misunderstandings? Having both students' and supervisors' perceptions would also offer a closer look at the interactions between them when they are trying to address mismatches. This would offer more information on the type of conflict resolution that they are using and its impact on the 
development of the situation. This could be done with retrospective interviews focusing on these moments in more detail, interviews or log book writing that take place just after the meeting, or live observation of such episodes.

Second, large-scale and longitudinal quantitative studies would also be worth carrying out in order to deepen our understanding of the issue. They could investigate the following aspects: the prevalence of misfit experiences among doctoral students, the most frequent types of misfits experiences (e.g., related to the content or the research project or to the supervision style), the influence of the strength and types of the misfit on doctoral students' outcomes (e.g., motivation, emotional well-being, persistence in the $\mathrm{PhD}$ ) and the individual characteristics likely to help regulate the incongruences.

Third, there would be an interest in implementing interventions aiming at helping $\mathrm{PhD}$ students and their supervisor to discuss a possible lack of fit (e.g., monthly meetings on specific aspects of the doctoral experience), and to assess their impact on the doctoral process and outcomes.

\section{Pragmatic Application}

Interventions like these that allow both students and supervisors to make explicit their needs, styles, expectations, and views of research would be of great importance, both at the start of the $\mathrm{PhD}$ and regularly during the doctoral journey. At the start of the process, for example, when recruiting $\mathrm{PhD}$ students, interviews should be as realistic as possible and focus not only on the research project to come, but also on what the daily work is going to be like, what type of supervision students are going to receive, etc. There could also be a short trial period where the newcomer joins the team for a couple of days to see what it is like to work in the department. During the doctoral journey, there is a need to regularly take some time to take stock on how the students feel in the PhD in general as well as with their research project, the supervision they receive, their integration with their doctoral peers, the culture of the department, etc. Such discussions often sound burdensome in academics' intense schedules but they are likely to save a lot of time in the end.

In addition, when $\mathrm{PhD}$ students are facing incompatibilities with their supervisor they often feel lonely, misunderstood, and at odds with their environment, and they would benefit from sharing these concerns with others, such as peer doctoral students in informal conversations, but also by means of more organized support groups or individual support (e.g., coaching). In the same line, it is important that doctoral students have other resource persons than the supervisor they can turn to when the bilateral collaboration gets harder. These persons may guide the students in a different way that will help them draw closer to their supervisor.

Finally, an issue that has already been raised is the lack of training that researchers are offered when entering academic positions (Halse, 2011). They are often selected on the basis of their research competences and may have few skills or training in other areas such as team management, doctoral supervision, etc. They learn when doing and improve through trial and error but would benefit from an increased and more specific support. Appropriate support and training focusing on the new tasks and responsibilities that they need to handle would be valuable for their professional development and the well-being and efficiency of their team. With regard to the training sessions that can be organized to help them support their students, these need to focus both on good practice in supervising them (e.g., Lee, Dennis \& Campbell, 2007) but also perhaps on good practice in how to adapt to students' personalities and needs. 


\section{References}

Acker, S., Hill, T., \& Black, E. (1994). Thesis supervision in the social sciences: Managed or negotiated? Higher Education, 28(4), 483-498. doi: 10.1007/BF01383939.

Andres, L., Bengtsen, S., del Pilar Gallego Castaño, L., Crossouard, B., Keefer, J., \& Pyhältö, K. (2015). Drivers and interpretations of doctoral education today: National comparisons. Frontline Learning Research, 3(3), 5-22. doi: 10.14786/flr.v3i3.177

Bair, C. R., \& Haworth, J. G. (2004). Doctoral student attrition and persistence: A meta-synthesis of research. In J. C. Smart (Ed.), Higher education: Handbook of theory and research (pp. 481-534). The Netherlands: Kluwer Academic Publishers.

Barnes, B. J., \& Austin, A. E. (2009). The role of doctoral advisors: A look at advising from the advisor's perspective. Innovative Higher Education, 33, 297-315. doi: 10.1007/s10755-008-9084-x

Blanchet, A., \& Gotman, A. (2010). L'entretien: L'enquête et ses méthodes [The interview: The investigation and its methods] (2nd ed.). Paris: Armand Colin.

Bøgelund, P. (2015). How supervisors perceive $\mathrm{PhD}$ supervision - And how they practice it. International Journal of Doctoral Studies, 10, 39-55. Retrieved November 21, 2016, from https://www.informingscience.org/Publications/2096

Boyatzis, R. E. (1998). Transforming qualitative information: Thematic analysis and code development. Thousand Oaks, CA: Sage.

Braun, V., \& Clarke, V. (2006). Using thematic analysis in psychology. Qualitative Research in Psychology, 3, 77-101. doi: 10.1191/1478088706qp063oa

De Dreu, C., \& Weingart, L. (2003). Task versus relationship conflict, team performance, and team member satisfaction. Journal of Applied Psychology, 88, 741-749. doi: 10.1037/0021-9010.88.4.741

Desivilya, S. H., \& Yagil, D. (2005). Conflict management in work teams: The role of emotions in conflict management: The case of work teams. International Journal of Conflict Management, 16(1), 55-69.

Deuchar, R. (2008). Facilitator, director or critical friend? Contradiction and congruence in doctoral supervision styles. Teaching in Higher Education, 13(4), 489-500. doi: 10.1080/13562510802193905

Devos, C., Van der Linden, N., Boudrenghien, G., Azzi, A., Frenay, M., Galand, B., \& Klein, O. (2015). Doctoral supervision in the light of the three types of support promoted in self-determination theory. International Journal of Doctoral Studies, 10, 439-464. Retrieved November 21, 2016, from https://www.informingscience.org/Publications/2308

Edwards, J. R. (2008). Person-environment fit in organizations: An assessment of theoretical progress. The Academy of Management Annals, 2, 167-230. doi: 10.1080/19416520802211503

Edwards, J. R., Cable, D. M., Williamson, I. O., Lambert, L. S., \& Shipp, A. J. (2006). The phenomenology of fit: Linking the person and environment to the subjective experience of person-environment fit. Journal of Applied Psychology, 91(4), 802-827. doi: 10.1037/0021-9010.91.4.802

European Commission. (2011). Report of mapping exercise on doctoral training in Europe: Towards a common approach. Retrieved from http://ec.europa.eu/euraxess/pdf/research_policies/Report_of_Mapping_Exercise_on_Doctoral_Trainin g_FINAL.pdf

Fereday, J., \& Muir-Cochrane, E. (2006). Demonstrating rigor using thematic analysis: A hybrid approach of inductive and deductive coding and theme development. International Journal of Qualitative Methods, 5(1), 80-92. Retrieved November 21, 2016, from http://www.ualberta.ca/ iiqm/backissues/5_1/pdf/fereday.pdf

Gilgun, J. F. (2005). Qualitative research and family psychology. Journal of Family Psychology, 19(1), 4050. doi: 10.1037/0893-3200.19.1.40 
Greguras, G. J., \& Diefendorff, J. M. (2009). Different fits satisfy different needs: Linking personenvironment fit to employee attitudes and performance using self-determination theory. Journal of Applied Psychology, 94, 465-477. doi: 10.1037/a0014068

Gross, J. J. (2013). Emotion regulation: Taking stock and moving forward. Emotion, 13, 359-365. doi: $10.1037 / \mathrm{a} 0032135$

Halse, C. (2011). 'Becoming a supervisor': The impact of doctoral supervision on supervisors' learning. Studies in Higher Education, 36(5), 557-570. doi: 10.1080/03075079.2011.594593

Hollingsworth, M. A., \& Fassinger, R. E. (2002). The role of faculty mentors in the research training of counseling psychology doctoral students. Journal of Counseling Psychology, 49, 324-330. doi: 10.1037/0022-0167.49.3.324

Hsieh, H.-F., \& Shannon, S. E. (2005). Three approaches to qualitative content analysis. Qualitative Health Research, 15(9), 1277-1288. doi: 10.1177/1049732305276687

Jairam, D., \& Kahl Jr., D. H. (2012). Navigating the doctoral experience: The role of social support in successful degree completion. International Journal of Doctoral Studies, 7, 311-329. doi: 10.1007/s10212-016-0290-0

Jones, M. (2013). Issues in doctoral studies - Forty years of journal discussion: Where have we been and where are we going? International Journal of Doctoral Studies, 8, 83-104. Retrieved November 21, 2016, from https://www.informingscience.org/Publications/1871

Kam, B. H. (1997). Style and quality in research supervision: The supervisor dependency factor. Higher Education, 34, 81-103. doi: 10.1023/A:1002946922952

Kehm, B. M. (2006). Doctoral education in Europe and North America: A comparative analysis. In U. Teichler (Ed.), The formative years of scholars (pp. 67-78). London: Portland Press.

Kristof, A. L. (1996). Person-organization fit: An integrative review of its conceptualizations, measurement, and implications. Personnel Psychology, 49, 1-49. doi: 10.1111/j.1744-6570.1996.tb01790.x

Kristof-Brown, A. L., Zimmerman, R. D., \& Johnson, E. C. (2005). Consequences of individuals' fit at work: A meta-analysis of person-job, person-organization, person-group, and person-supervisor fit. Personnel Psychology, 58, 281-342. doi: 10.1111/j.1744-6570.2005.00672.x

Lazarus, R. S., \& Folkman, S. (1984). Stress, appraisal, and coping. New York: Springer.

Leclerc-Olive M. (2002). Temporalités biographiques: Lignes et nœuds [Biographical times: Lines and tangles]. Temporaliste, 44, 33-41.

Lee, A., Dennis, C., \& Campbell, P. (2007). Nature's guide for mentors. Nature, 447(7146), 791-797. doi: $10.1038 / 447791 \mathrm{a}$

Martinsuo, M., \& Turkulainen, V. (2011). Personal commitment, support and progress in doctoral studies. Studies in Higher Education, 36(1), 103-120. doi: 10.1080/03075070903469598

McLellan, E., MacQueen, K. M., \& Neidig, J. L. (2003). Beyond the qualitative interview: Data preparation and transcription. Field Methods, 15(1), 63-84. doi: 10.1177/1525822X02239573

Moos, R. H., \& Billings, A. G. (1982). Conceptualizing and measuring coping resources and processes. In L. Goldberger \& S. Breznitz (Eds.), Handbook of stress: Theoretical and clinical aspects (pp. 212230). New York: Free Press. doi: 10.1037/0021-843X.100.1.31

Oliver, D., Serovich, J. M., \& Mason, T. L. (2005). Constraints and opportunities with interview transcription: Towards reflective practice in HIV/AIDS intervention research. Social Forces, 84(2), 1273-1289. doi: $10.1007 / \mathrm{s} 10212-016-0290-0$

Paglis, L. L., Green, S. G., \& Bauer, T. N. (2006). Does adviser mentoring add value? A longitudinal study of mentoring and doctoral student outcomes. Research in Higher Education, 47(4), 451-476.

doi: $10.1007 / \mathrm{s} 11162-005-9003-2$ 
Pyhältö, K., Vekkaila, J., \& Keskinen, J. (2012). Exploring the fit between doctoral students' and supervisors' perceptions of resources and challenges vis-à-vis the doctoral journey. International Journal of Doctoral Studies, 7, 395-414. Retrieved November 21, 2016, from https://www.informingscience.org/Publications/1745

Rahim, M. A. (2002). Toward a theory of managing organizational conflict. The International Journal of Conflict Management, 13, 206-235. doi: 10.1108/eb022874

Sambrook, S., Stewart, J., \& Roberts, C. (2008). Doctoral supervision... A view from above, below and the middle! Journal of Further and Higher Education, 32(1), 71-84. doi: 10.1080/03098770701781473

Skinner, E., Edge, K., Altman, J., \& Sherwood, H. (2003). Searching for the structure of coping: A review and critique of category systems for classifying ways of coping. Psychological Bulletin, 129, 216-269. doi: 10.1037/0033-2909.129.2.216

Thompson, B. M., Brough, P., \& Schmidt, H. (2006). Supervisor and subordinate work-family values: Does similarity make a difference? International Journal of Stress Management, 13(1), 45-63. doi: $10.1037 / \mathrm{a} 0022170$

Vaismoradi, M., Turunen, H., \& Bondas, T. (2013). Content analysis and thematic analysis: Implications for conducting a qualitative descriptive study. Nursing \& Health Sciences, 15(3), 398-405. doi: $10.1111 /$ nhs. 12048

Wao, H. O., \& Onwuegbuzie, A. J. (2011). A mixed research investigation of factors related to time to the doctorate in education. International Journal of Doctoral Studies, 6, 115-134. Retrieved November 21, 2016, from https://www.informingscience.org/Publications/1505

Weiten, W. \& Lloyd, M. A. (2008). Psychology applied to modern life (9th ed.). Wadsworth: Cengage Learning.

Wrosch, C., Scheier, M. F., Miller, G. E., Schulz, R., \& Carver, C. S. (2003). Adaptive self-regulation of unattainable goals: Goal disengagement, goal reengagement, and subjective well-being. Personality and Social Psychology Bulletin, 29(12), 1494-1508. doi: 10.1177/0146167203256921

Zhou, J. (2015). International students' motivation to pursue and complete a Ph.D. in the U.S. Higher Education, 69, 719-733. doi: 10.1007/s10734-014-9802-5

\section{Appendix}

List of the themes that were addressed in the interviews

- The different moments/tasks in the PhD and how easy or difficult they are for the participants (i.e. writing the initial research project, constituting the jury, participating in conferences, writing and submitting papers, defending the thesis at the end, etc.)

- Why and how they started a PhD

- Their expectations with regard to the $\mathrm{PhD}$ and the academic and research world in general.

- The confrontation between these views and reality.

- Relationship with the supervisor

- Relationships with the doctoral peers

- The role played by the relatives

- The working climate in their department

- Their material environment (e.g. office, specific material they need, etc.)

- Their teaching and other assignments (e.g. courses to give, lab activities to organize, help on side projects, etc.)

- Doctoral school 


\section{Biographies}

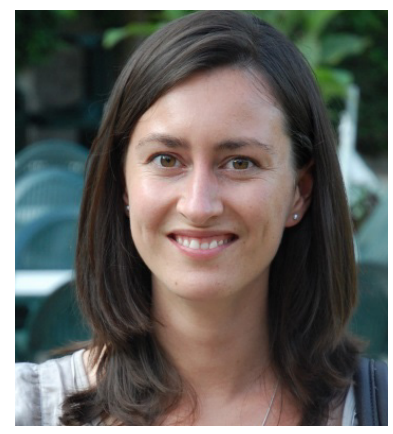

Christelle Devos, $\mathrm{PhD}$, is a post-doctoral researcher in educational psychology at the Université catholique de Louvain, Belgium. Her research interests include doctoral engagement and persistence, training transfer and beginning teachers' experiences. More information about her can be found on http://www.researchgate.net/profile/Christelle_Devos. She can be reached at: christelle.devos@uclouvain.be

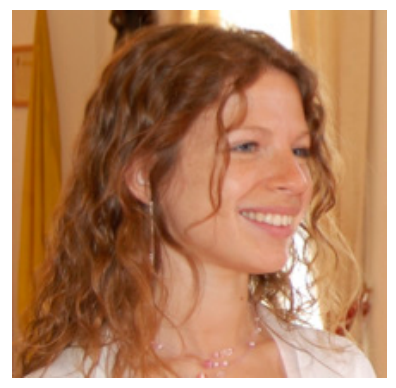

Gentiane Boudrenghien, $\mathrm{PhD}$, is a post-doctoral researcher in educational psychology at the Université catholique de Louvain, Belgium. Her research interests include doctoral engagement, educational and professional transitions, and persistence in academic or professional goals. She can be reached at: gentiane.boudrenghien@uclouvain.be.

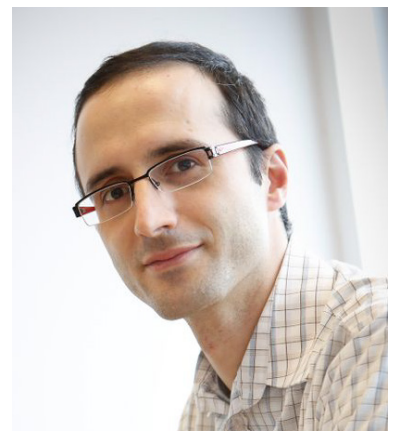

Nicolas Van der Linden, $\mathrm{PhD}$, is a post-doctoral researcher in social psychology at the Université Libre de Bruxelles, Belgium. His research interests include doctoral engagement and persistence, diary-based learning, social stereotypes, and intergroup conflicts. More information about him can be found on http://www.psychopsysoc.site.ulb.ac.be/equipe/nicolas-van-der-linden. He can be reached at nivdlind@ulb.ac.be.

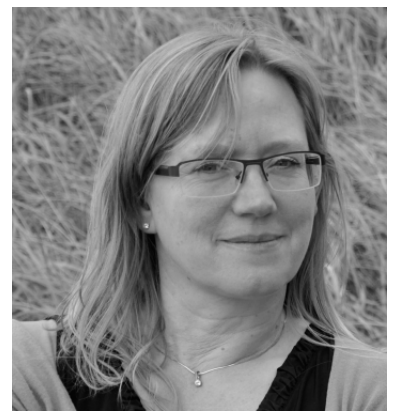

Mariane Frenay, $\mathrm{PhD}$, is a Professor at the Université catholique de Louvain, Belgium. Her research interests include students' persistence and academic achievement, learning and professional development in higher education. More information about her can be found on http://www.uclouvain.be/mariane.frenay. She can be reached at: mariane.frenay@uclouvain.be 


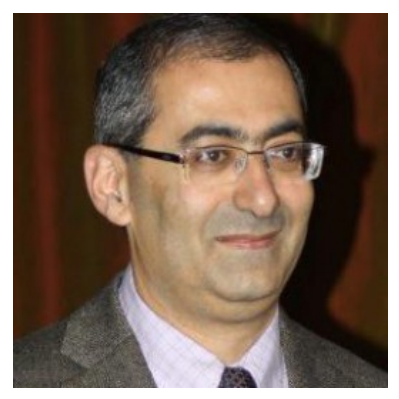

Assaad Azzi, $\mathrm{PhD}$, is a Professor and Head of the Social psychology unit at the Université Libre de Bruxelles, Belgium. His research interests include intergroup relations, acculturation, discrimination, and perception of justice. More information about him can be found on http://www.psycho-psysoc.site.ulb.ac.be/equipe/assaad-azzi. He can be reached at: aazzi@ulb.ac.be.

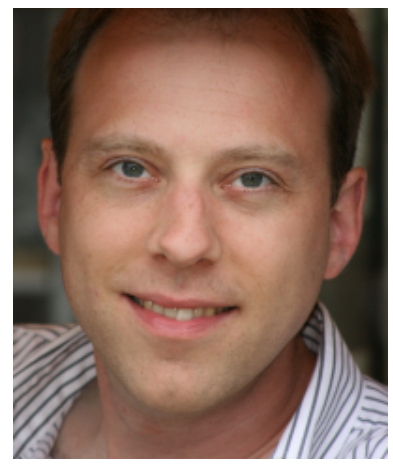

Benoît Galand, $\mathrm{PhD}$, is a Professor at the Université catholique de Louvain, Belgium. His research interests include motivation and engagement in learning, violence and bullying in schools, and teachers' professional practices. More information about him can be found on http://www.uclouvain.be/benoit.galand. He can be reached at: benoit.galand@uclouvain.be.

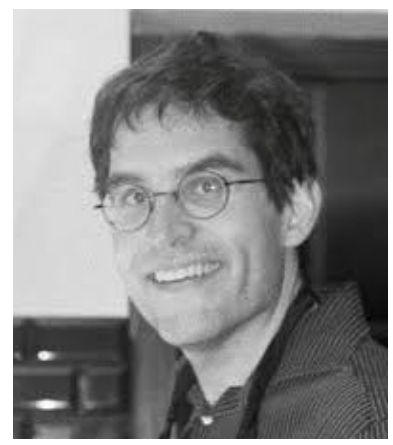

Olivier Klein, $\mathrm{PhD}$, is a Professor and head of the Center for Social and Cultural Psychology at the Université Libre de Bruxelles, Belgium. His research interests concern social stereotypes, objectivation and dehumanization, and social influences on memory. He also is chief editor (with Céline Darnon) of the International Review of Social Psychology. More information about him can be found on http://www.psycho-psysoc.site.ulb.ac.be/equipe/olivier-klein. He can be reached at: oklein@ulb.ac.be. 